\title{
Peter Resteghini: Diagnostic musculoskeletal ultrasound and guided injection: a practical guide
}

\section{Thieme Verlag, New York, Stuttgart, Delhi, Rio de Janeiro, 2017, 192 pp, Softcover (KT), EUR (D) 94,99 EUR (A) 97,70 CHF 109,00, ISBN: 978-3-13-220381-5}

\author{
Alain G. Graftiaux ${ }^{1} \cdot$ Pierre Kehr $^{1}$
}

Received: 6 April 2018 / Accepted: 20 May 2018 / Published online: 4 June 2018

(c) Springer-Verlag France SAS, part of Springer Nature 2018

This book is intended to the various specialist surgeons and doctors who are interested have echography for musculoskeletal pathologies. Indeed, more and more of doctors use the echographs until in their cabinets and operating rooms with a diagnostic but also therapeutic aim. This book will bring useful precise details and the means to them of carrying out infiltrations under echographic control. This book treats various articulations of the upper limbs but so lower. After a chapter of general information showing specificities of various fabrics, the various articulations are approached with many illustrations showing the position of the probe and the images of the various elements anatomical with associated pathologies. The techniques of injection are then described with the description of the hardware requirement.

A book for all those which want to be traineed with echography.

\section{Compliance with ethical standards}

Conflict of interest The author(s) declare that they have no competing interests.
Pierre Kehr

Strasbourg, France 